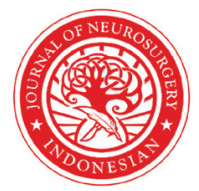

Indonesian Journal of Neurosurgery

\section{The correlation between the degree of traumatic brain injury based on the glasgow coma scale (GCS) and the emersion of post concussion syndrome (PCS) acute onset in the patients of post traumatic brain injury at Dr. M. Djamil Hospital Padang}

\author{
Muhammad Reza Azriyantha ${ }^{1 *}$, Syaiful Saanin ${ }^{2}$, Hesty Lidya Ningsih²
}

\section{ABSTRACT}

Background: Traumatic brain injury is the main cause of death in the population under the age of 45 years, and the fourth leading cause of death in the entire of population. Based on the degree of traumatic brain injury, it is commonly categorized based on the Glasgow Coma Scale (GCS). Post-Concussion Syndrome (PCS) is the set of somatic, emotional / behavioral and cognitive symptoms that occur after a traumatic brain injury.

Objective: The aim of this study was to find out the prevalence and correlation of the degree of traumatic brain injury based on the Glasgow Coma Scale (GCS) and the emersion of Post-Concussion Syndrome (PCS) acute onset in patients with head injuries

Methods: This study was a cross-sectional analytic study of patients who experienced Post-Concussion Syndrome (PCS) after traumatic brain injury at DR. M. Djamil Hospital Padang in 2020 from June to November 2020. Data were collected by filling in a questionnaire (The Rivermead Post Concussion Symptoms Questionnaire) and medical record data of neurosurgical patients that met the inclusion and exclusion criteria.

'Resident of General Surgery Department Faculty of Medicine, Andalas University / Dr. M. Djamil Hospital,

Padang

${ }^{2}$ Department of Neurosurgery Faculty of Medicine, Andalas University / Dr. M. Djamil Hospital, Padang

\section{*Corresponding to :}

Muhammad Reza Azriyantha; Resident of General Surgery Department Faculty of Medicine, Andalas University / Dr. M. Djamil Hospital, Padang;

ejabagan@gmail.com

Results: It indicated that 70 patients were included in the inclusion criteria of this study. A total of 38 (54.3) respondents did not undergo the acute onset of PCS, meanwhile respondents who experienced acute onset of PCS were 32 (45.7) respondents. The results showed that $25(67.6 \%)$ respondents with mild traumatic brain injury had PCS acute onset, while 4 (17.4\%) respondents with moderate degree of traumatic brain injury had PCS acute onset, and 4 (17.4\%) respondents had PCS acute onset PCS $3(30 \%)$ respondents experienced severe traumatic brain injury with acute onset PCS and statistically the difference in the proportion of data from each of these variables was significant with a $p$-value of 0.0001 . The results of statistical tests showed that $p$ value $>0.05$ on the correlation between PCS and GCS, thus, it can be concluded that there was no correlation between the direction of the relationship between PCS and GCS.

Conclusion: There was no correlation between the degree of traumatic brain injury based on GCS and the incidence of PCS acute onset, either it was unidirectional or vice versa in patients with head injuries at RSUP M. Djamil Padang.

Keywords: Traumatic brain injury, GCS, PCS

Cite This Article: Azriyantha, M.R., Saanin, S., Ningsih, H.L. 2021. The correlation between the degree of traumatic brain injury based on the glasgow coma scale (GCS) and the emersion of post concussion syndrome (PCS) acute onset in the patients of post traumatic brain injury at Dr. M. Djamil Hospital Padang. Indonesian Journal of Neurosurgery 4(1): 4-10. D0I: 10.15562/ ijn.v4i1.170

\section{INTRODUCTION}

Traumatic brain injury is the main cause of death in the population under 45 years of age, and is the $4^{\text {th }}$ leading cause of death in the entire population. The incidence of traumatic brain injury in America ranges from $132-367$ per 100,000 population with the highest population group that aged 1524 years. The frequency of head injuries in males and females was 2-2.8: 1, most of them had minor head injuries (80\%), the rest had moderate head injuries (CKS) $(10 \%)$, and severe head injuries (CKB) (10\%). ${ }^{1}$ In accordance with data from Basic Health Research (RISKESDAS) in 2018, the proportion of head injuries nationally was $11.9 \%$, with the proportion of head injuries in West Sumatra province 14.3\%, where at Dr. M Djamil Padang, there were 356 traumatic brain injury cases in 2017, 505 cases occurred in 2018 at RSUP Dr. M Djamil Padang. ${ }^{2}$

Based on the degree of traumatic brain 
injury, it is commonly categorized based on Glasgow Coma Scale (GCS). GCS assesses the level of consciousness based on three clinical components, namely the response of opening the eyes, motor and verbal responses. The GCS score is the total value of the three components, namely between $3-15$. A value of 3 means that the patient does not respond to any stimuli, while a value of 15 implies that the patient is fully aware. The assessment of GCS is usually undertaken during trauma resuscitation. The classification of head injuries is divided into 3 where severe traumatic brain injury with a GCS score of 3 to 8 , moderate traumatic brain injury with a GCS score of 9 to 13 , mild traumatic brain injury with a GCS score of 14 to $15 .^{3}$

Post Concussion Syndrome (PCS) is a collection of somatic, emotional / behavioral and cognitive symptoms that occur after the traumatic brain injury. ${ }^{4}$ The somatic symptoms are headache, fatigue, sleep disturbances, nausea, vomiting, visual disturbances, tinnitus, vertigo, sensitivity to sound and light. Emotional / behavioral symptoms consist of a low tolerance for frustration, anxiety, emotional build-up, depression, anxiety, and personality changes. Whereas, the cognitive symptoms consist of decreased thinking responses, decreased concentration, mental fogginess, the difficulty of learning and remembering disorganization, the ability of problem solving has reduced. ${ }^{4}$

Based on the onset, PCS is classified as acute (symptoms emerge the less than one month after injury), sub-acute ( $>1-12$ months), and chronic (more than a year). About $40-50 \%$ of patients will undergo PCS in the first to third month post-onset, and $25 \%$ of patients at a year of onset. ${ }^{4,5}$

Research on persistent cognitive impairment in adult patients without intracranial hemorrhage who have survived after getting the treatment at the Intensive Care Unit (ICU) show that $74 \%$ of patients experience the cognitive impairment. ${ }^{6}$ During follow up at 2 years, persistent cognitive dysfunction almost occurs twofold in patients with head injuries and head fractures than those who do not undergo the incident. During the period of follow up 30 year of patients with cognitive impairment after traumatic brain injury, the group of female patient tends to maintain its cognitive level, but the male group shows worsening. Younger sufferers have the possibility to maintain or even improve cognitive function. ${ }^{78}$

The degradation of cognitive function namely $60 \%$ of memory impairment occurs after minor traumatic brain injury, while it is $50 \%$ in moderate traumatic brain injury, and $20 \%$ in post severe traumatic brain injury. The difficulties of concentration occurs in post minor traumatic brain injury (65\%), post moderate traumatic brain injury (60\%), and post severe traumatic brain injury (40\%) patients. Fatigue experienced by patients about $60 \%$ after minor traumatic brain injury and moderate traumatic brain injury and 35\% after severe traumatic brain injury. The empirical studies report that worry become specific symptom in PCS and more often in minor traumatic brain injury than moderate or severe traumatic brain injury population. ${ }^{9}$

The prevalence of post-injury headache is $30-90 \%$, and possibly occur as the result of minor, moderate, or severe head injuries. ${ }^{10}$ Post-injury headaches occur in $50-80 \%$ immediately after the incident and can continue for 1-2 years later in about $20-30 \% .{ }^{11}$ The review of scientific literature by Seifert \& Evans reported that $85 \%$ of post-injury headache are the tension-type headache. ${ }^{12}$ The study on soldiers shows different results that $78 \%$ of headache symptoms are the migrainetype headache. ${ }^{13}$ Moreover, another study shows that migraine-type headache and tension-type headache have almost the same prevalence after the head injuries incidence, namely $39 \%$ in migraine headache and $34.1 \%$ in tension type headache. ${ }^{14}$ The moderate or severe head injuries headaches are three times painful more than post minor head injuries. ${ }^{15,16}$

Meanwhile, what to concern is the incidence of traumatic brain injury and other symptoms namely Post Concussion Syndrome with low awareness of patient to get optimal treatment of Post Concussion Syndrome in the medical field, so that the Post Concussion Syndrome incident continues and interrupt patient's daily activities.

\section{METHODS}

This study is an analytical study using the Cross Sectional method for Post Concussion Syndrome (PCS) patients after traumatic brain injury in DR. M. Djamil Hospital Padang in June to November 2020. The number of samples was determined using the formula of Lemeshow Modification. The inclusion criteria in this study were: Patients with head injuries in DR. M. Djamil Hospital Padang in the study period, patients with symptoms of acute Post Concussion Syndrome (PCS) or less than a month after the incident, aged more than 18 years, patients out of ward with no disability, minimum level of education is elementary school education / equivalent, and the patient want to participate in this study after the explanation has been given.

Moreover, the exclusion criteria in this study were patients who had a history of complaints that similar with complaint of Post Concussion Syndrome before the incidence of traumatic brain injury and patients who had history of comorbidities with similar complaint as complaint of Post Concussion Syndrome before traumatic brain injury.

The data of this study were collected by questionnaire (The Rivermead Post Concussion Symptoms Questionnaire) and interviewing patients. The data on the level of traumatic brain injury based on GCS were collected from the medical records of neurosurgical patients at DR. M. Djamil Hospital Padang. The data were presented and analyzed using SPSS version 22. They are presented on tables. The univariate analysis was performed to describe the characteristic of basis study data. The bivariate analysis with the ChiSquare test was performed to know the correlation between GCS and PCS. It is stated that the result is accepted if the $\mathrm{P}$ value $<0.05$

\section{RESULTS}

Table 1 shows that mean of research's respondents age is $39,97 \pm 17,21$ years old. More than half of the respondents are male $48(68,6)$ respondents. For traumatic brain injury incidence we obtained that $37(52,9)$ respondents with minor 
Table 1. Characteristics of Research's Respondents

\begin{tabular}{lcc}
\multicolumn{1}{c}{ Characteristics } & Mean \pm SD & $\mathbf{f}(\mathbf{)})$ \\
\hline Age & $39,97 \pm 17,21$ & \\
Gender & & $48(68,6)$ \\
- Male & $22(31,4)$ \\
- Female & \\
Traumatic brain injury severity & \\
- Minor (GCS 14-15) & $37(52,9)$ \\
- Moderate (GCS 9-13) & $23(32,9)$ \\
- SevereGCS 3-8) & $10(14,3)$ \\
& \\
Post Concussion Syndrome (PCS) & \\
- Negative & $38(54,3)$ \\
- Posittive & $32(45,7)$ \\
\hline
\end{tabular}

Table 2. Characteristics of Respondents with Acute PCS Onset

\begin{tabular}{lcc}
\multicolumn{1}{c}{ Characteristics } & Mean \pm SD & f (\%) \\
\hline Age & $41,19 \pm 18,48$ \\
Gender & \\
- Male & \\
- Female & $23(71,9)$ \\
Traumatic brain injury Severity & $9(28,1)$ \\
- Minor (GCS 14-15) & \\
- Moderate (GCS 9-13) & $25(67,6)$ \\
- Severe (GCS 3-8) & $4(17,4)$ \\
& & $3(30)$ \\
\hline
\end{tabular}

Table 3. Distribution of lowest, Highest, and Mean Total Score of Respondents with Acute PCS Onset

\begin{tabular}{lccc}
\hline & \multicolumn{3}{c}{ Acute PCS Onset } \\
\cline { 2 - 4 } Traumatic brain injury Severity & Lowest & Highest & Mean \\
\cline { 2 - 4 } Minor (GCS 14-15) & 8 & 30 & 17,2 \\
Moderate (GCS 9-13) & 4 & 14 & 11,3 \\
Severe (GCS 3-8) & 10 & 17 & 13 \\
\hline
\end{tabular}

Table 4. Distribution of Overall Respondents Acute PCS Onset Symptoms

\begin{tabular}{lc}
\multicolumn{1}{c}{ Symptoms } & $\mathbf{f ( \% )}$ \\
\hline - Headache & $32(100)$ \\
- Dizziness & $30(93,7)$ \\
- Nausea / vomitting & $25(78,1)$ \\
- Hearing sensitivity disorder & $4(12,5)$ \\
- Difficulty to start sleeping & $25(78,1)$ \\
- Fatigue & $22(68,8)$ \\
- Easy to get angry & $24(75)$ \\
- Depressed feeling & $23(71,8)$ \\
- Frustration / Impatient & $25(78,1)$ \\
- Forgetfulness / memory disorder & $18(56,3)$ \\
- Concentration difficulty & $22(68,8)$ \\
- Difficulty of thinking & $23(71,8)$ \\
- Vision disorder & $6(18,7)$ \\
- Light sensitivity & $8(25)$ \\
- Double vision & $9(28,1)$ \\
- Anxiety & $27(84,4)$ \\
\hline
\end{tabular}

traumatic brain injury, then followed by moderate traumatic brain injury 23(32,9), and the last is severe traumatic brain injury 10(14,3). Respondents with negative acute PCS onset are 38(54,3), meanwhile respondents with positive acute PCS onset are 32(45,7) respondents.

Based on Table 2 we concluded that age of respondents with acute PCS onset is $41,19 \pm 18,48$ years old. More than half of the respondents with acute PCS onset are males $23(71,9)$. For the severity of the traumatic brain injury, 25(67,6) of respondents with minor traumatic brain injury had acute PCS onset, meanwhile respondents with moderate traumatic brain injury who had acute PCS onset are $4(17,4)$, and respondents with severe traumatic brain injury who had acute PCS onset are 3(30) respondents.

Table 3 shows that total mean value of minor traumatic brain injury with acute PCS onset is 17,2 with lowest total score is 8 and highest total score is 30 . In moderate traumatic brain injury, mean value of acute PCS onset is 11,3 with lowest total score is 4 and highest total score is 14 . Then, in severe traumatic brain injury total mean value of acute PCS onset is 13, with lowest total score is 10 and highest total score is 17.

Table 4 shows that common symptoms of acute PCS onset are headache 32(100), dizziness $30(93,7)$, and anxiety $27(84,4)$. On the other hands, rare symptoms of acute PCS onset are hearing sensitivity disorder 4(12,5), vision disturbances $6(18,7)$, and light sensitivity $8(25)$.

Table 5 shows that the most common symptom complained by patients with PCS acute onset was headache 25(100), dizziness 23(92), and anxiety 22(88), etc.

Table 6 shows that $25(67,6 \%)$ of respondents with minor traumatic brain injury would acquire acute PCS onset, then in the group of moderate traumatic brain injury, $4(17,4 \%)$ of respondents would acquire acute PCS Onset, and 3(30\%) of respondents with severe traumatic brain injury would acquire acute PCS onset. Statistically, result of the data differences from each variable is significant with p-value 0,0001

Table 7 shows correlation between PCS and GCS based on Spearman Correlation Analysis is $-0,145$. According to 
Table 5. Symptoms Distribution of each traumatic brain injury severity with Acute PCS Onset

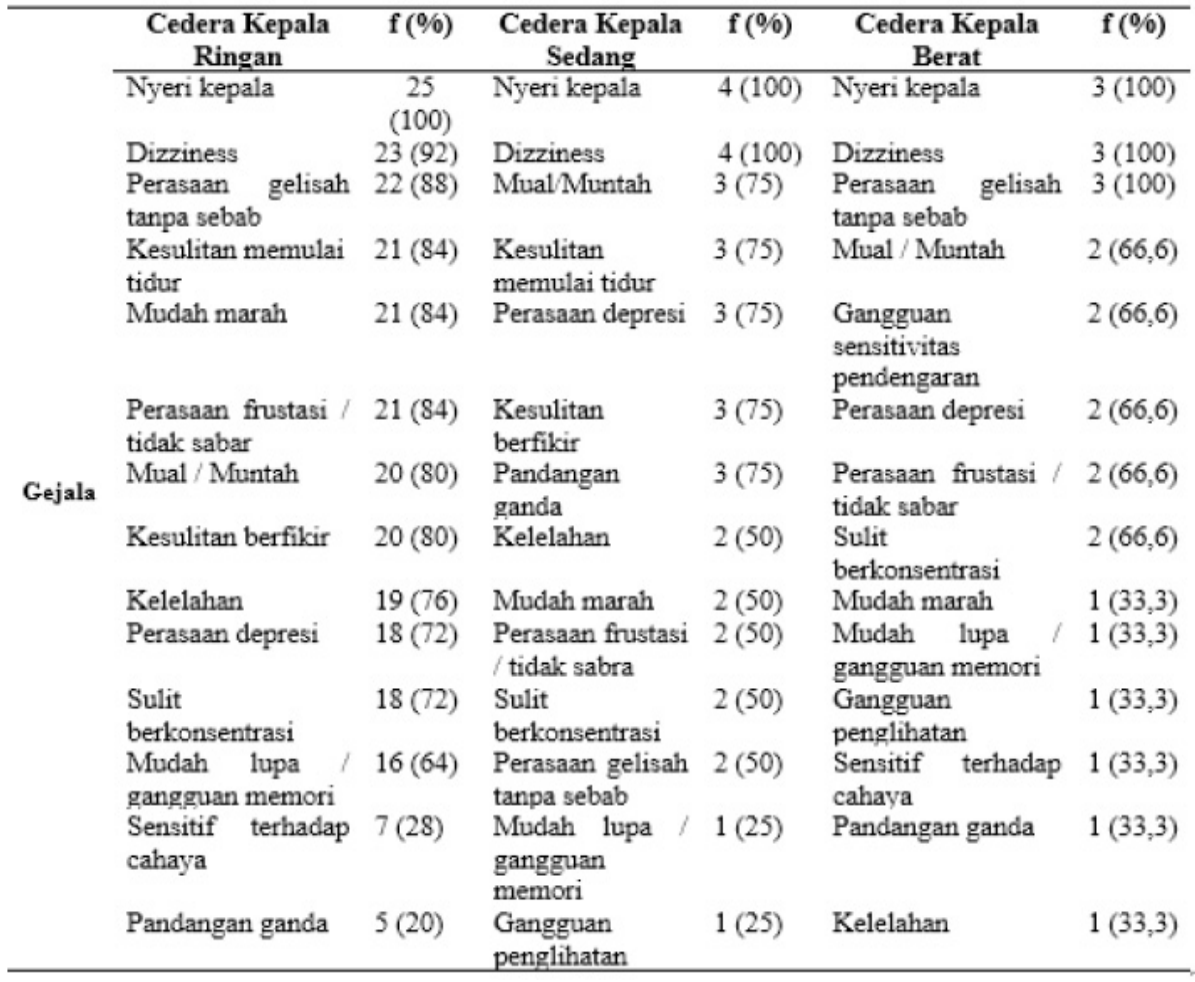

Table 6. Relationship of Traumatic brain injury Based on GCS with Acute PCS Onset Manifestation Based on Data Proportion's Differences

\begin{tabular}{lcccc}
\hline \multirow{2}{*}{$\begin{array}{c}\text { Traumatic brain } \\
\text { injury Severity }\end{array}$} & \multicolumn{2}{c}{ PCS } & \multirow{2}{*}{ Total } & p-value \\
\cline { 2 - 3 } & Positive & Negative & & \\
\hline Minor & $\mathbf{2 5 ( 6 7 , 6 \% )}$ & $\mathbf{1 2 ( 3 2 , 4 \% )}$ & 37 & 0,0001 \\
Moderate & $4(17,4 \%)$ & $19(82,6 \%)$ & 23 & \\
Severe & $3(30 \%)$ & $7(70 \%)$ & 10 & \\
\hline
\end{tabular}

Table 7. Correlation of Relationship Direction Between Variables

\begin{tabular}{|c|c|c|c|c|}
\hline \multicolumn{5}{|c|}{ Correlations } \\
\hline & & & PCS & GCS \\
\hline \multirow[t]{6}{*}{ Spearman's rho } & PCS & Correlation Coefficient & 1,000 &,- 145 \\
\hline & & Sig. (2-tailed) & & ,672 \\
\hline & & $\mathrm{N}$ & 70 & 70 \\
\hline & GCS & Correlation Coefficient &,- 145 & 1,000 \\
\hline & & Sig. (2-tailed) & ,672 & \\
\hline & & $\mathrm{N}$ & 70 & 70 \\
\hline
\end{tabular}

${ }^{* *}$. Correlation is significant at the 0,01 level (2-tailed)

Table 8. Correlations between variables

\begin{tabular}{cccc}
\hline Variable & r count & $\boldsymbol{r}$ table & Conclusion \\
\hline PCS-GCS & 0,145 & 0,235 & No correlation \\
\hline
\end{tabular}

relationship range between independent and dependent variables, there were low relationship between these 2 variables with negative and positive relationship direction. And statistic test shows that value of $\mathrm{p}>0,05$, so that we conclude that there were no correlation between PCS and GCS

Table 8 shows that PCS variable to GCS variable obtained $r$ value count $<r$ table $(0,145<0,235)$, then in this research $\mathrm{HO}$ is accepted dan $\mathrm{Ha}$ is rejected, which is mean there was no correlation between PCS with GCS

From the data obtained above, it is concluded that acute PCS onset is mostly happened in minor traumatic brain injury, followed by severe traumatic brain injury, and lastly in moderate traumatic brain injury. So that is explained there were no relationship between severity of traumatic brain injury based on GCS with acute PCS onset, either unidirectional or vice versa relationship in traumatic brain injury patients in RSUP M. Djamil Padang.

\section{DISCUSSION}

In this study, the researcher revealed the head injuries and sequelae that are caused by structural changes and metabolic reactions in the brain, which is called Post-Concussion Syndrome (PCS). ${ }^{4}$ Traumatic brain injury is defined as a complex pathophysiological process in the brain that involves biomechanical forces of traumatic events. ${ }^{20}$ The pathophysiology of PCS is not completely clear, however, the pathophysiology of PCS is inseparable from the pathophysiology of traumatic brain injury itself. ${ }^{30}$

In this study, the researcher attempts to link the incidence of head injuries that classified in accordance with the Glasgow Coma Scale (GCS) scoring with the emersion PCS acute-onset in patients with head injuries. Dealing with the research result has been described in the previous chapter, the researcher has obtained some discussions in this chapter.

The results of this study indicated that more than half of the respondents, 37 (52.9) respondents experienced a mild degree of traumatic brain injury, it also was followed by a moderate degree of traumatic brain injury, namely 23 (32.9) and the last, the degree of severe 
traumatic brain injury was 10 (14.3). This is consistent with research conducted by Jagoda et al. in 2006 which asserted that of all head injuries that occurred, most had mild head injuries (80\%), the rest had moderate head injuries (10\%), and severe head injuries (10\%). ${ }^{1}$

Whereas, for the incident of acuteonset PCS in patients with head injuries, this study revealed that 32 (45.7) of the total respondents experienced acute-onset PCS, this is in line with the literature from Academy Emergency Medicine in 2001 in America argued that about $40-50 \%$ of patients would experience PCS in the first to third months after a traumatic brain injury. ${ }^{5}$

For the age range of patients with acute onset PCS in this study, the researcher obtained a mean of $41.19+18.48$ years. In another study conducted by Brenda et al. showed that the incidence of PCS was more common in those over 50 years of age. In the same study conducted by Brenda et al. in 2018 at the Toronto Western Hospital argued that the incidence of acute-onset PCS in women was higher than in men. ${ }^{52}$ However, the researcher found that the incidence rate of acute-onset PCS was different in men $23(71,9)$ and it was more than women 9 (28.1). Meanwhile, this study is in line with other studies that conducted by Asres et al. In 2018 at Hawassa University Hospital, it was found that the male gender (75 people) experienced more acute onset of PCS rather than women (39 people). ${ }^{53}$

Based on the literature, PostConcussion Syndrome (PCS) is a set of symptoms consisting of somatic, emotional / behavioral and cognitive symptoms. ${ }^{4}$ Then, somatic symptoms consist of headache, fatigue, sleep disturbances, nausea, vomiting, visual disturbances, tinnitus, vertigo, sensitivity to sound and light. Meanwhile, emotional / behavioral symptoms consist of low tolerance for frustration, anxiety, emotional increase, depression, anxiety, and personality changes. Moreover, the cognitive symptoms consist of decreased thinking responses, decreased concentration, mental fogginess, the difficulty of learning and remembering disorganization, the ability of problem solving has reduced. Responding to the symptoms above, the researcher found that headache was 32 (100), dizziness was 30 (93.7) and feeling restless without cause was 27 (84.4) and those were the three most common symptoms that complained of by respondents who experienced PCS while the symptoms rarely felt by respondents were hearing sensitivity impairment 4 (12.5), visual impairment 6 (18.7), and sensitive to light 8 (25).

According to Hoffman JM et al in 2011, said that headaches were the most common symptom complained by patients with minor, moderate or severe head injuries. Researchers also found the same thing in this study that headache is the most common symptom that occurs in each traumatic brain injury severity, whereas at each degree of traumatic brain injury, headache complaints have a percentage of $100 \%$ or are always complained followed by dizziness (23(92) in minor traumatic brain injury, 4(100) in moderate traumatic brain injury and 3(100) in severe traumatic brain injury. Whereas, nausea/ vomiting 3(75) occurred in moderate head injuries, where these symptoms were the other most common after headache. Whereas, for the rare symptoms that were not found in this study, it was found that hearing sensitivity symptoms were the most uncommon symptom in minor head injuries 2(8) and moderate head injuries $0(0)$, while for severe head injuries with difficulty thinking is a symptom that there is no complaint (0).

PCS is a collection of symptoms that occur immediately after the presence of a traumatic brain injury that mostly improved after third week after traumatic brain injury. However, PCS can be chronic and persistent. ${ }^{55}$ PCS is a group of symptoms experienced by someone who can occur in minor, moderate, or severe traumatic brain injury. ${ }^{56}$

According to a research conducted by Mullaly et al in 2017 in Boston, USA, The incidence of PCS is more common in minor head injuries, reaching nearly $80 \%$ compared to moderate and severe head injuries. Based on the studies above, it was found that PCS was more dominant or more common in minor head injuries than moderate and severe head injuries, as similar things was obtained by Mullaly et al. $^{23}$
According to a research conducted by Permenter CM et all, in 2020 in Puerto Rico and Miami trying to relate between traumatic brain injury severity with the incidence of PCS, It was found that there was no relationship between the severity of traumatic brain injury with the incidence of acute-onset PCS, both unidirectional and reverse relationship on patients who suffered from traumatic brain injury at Dr. M. Djamil Hospital.

This study shows that Post Concussion Syndrome (PCS) is a true collection of symptoms that are more common in minor traumatic brain injury compared to moderate or severe traumatic brain injury. PCS predominantly occurs in minor traumatic brain injury. This is expected to be the data and the basis for the clinician to provide a better education and treatment for all of the patient with head injuries especially in minor head injuries.

\section{CONCLUSIONS}

The general characteristic of respondents who experienced traumatic brain injury in this study were more men than women, where men were $48(68,6)$ respondents and women $22(31,4)$ respondents. And it is also known that the average age of the respondents who suffered head injuries namely $39,97 \pm 17,21$. Then, based on the degree of traumatic brain injury of the respondents of this study it is known that minor traumatic brain injury had the highest number of 37(52,9), moderate traumatic brain injury $23(32,9)$ and severe traumatic brain injury $10(14,3)$.

It is known that less than half of the respondents in this study $32(45,7)$ experienced Post Concussion Syndrome acute onset and the remaining 38(54,3) had no Post Concussion Syndrome acute onset. Of the 32(45,7) respondents who experienced Post Concussion Syndrome acute onset it was found that $25(67,6)$ occurred at minor traumatic brain injury, $3(30)$ at severe traumatic brain injury and $4(17,4)$ at moderate traumatic brain injury.

There was no correlation between the degree of traumatic brain injury based on GCS and the incidence of PCS acute onset, either it was unidirectional or vice versa in patients with head injuries at RSUP M. Djamil Padang. 


\section{DECLARATIONS}

\section{Ethical approval}

Has met the requirements of the ethical clearance

\section{REFERENCES}

1. Jagoda A, Bruns JJr. Prehospital Management of Traumatic Brain Injury. Theories and Practice, United Kingdom: Taylor \& Francis; 2006.

2. Badan Penelitian dan Pengembangan Kesehatan. Riset Kesehatan Dasar (RISKESDAS) 2018. Laporan Nasional 2018. Jakarta; 2019.

3. Teasdale G, Jennett B. Assessment of coma and impaired. Lancet. 1974; 2: 81-4.

4. Ruff RM, Grant I. Post Concussional Disorder Background to DSM-IV and Future Consideration. California: University of California; 1996.

5. Bazarian JJ, Atabaki S. Predicting Post Concussion Syndrome After Traumatic Brain Injury. Academic Emergency Medicine, 2001:8:788-795.

6. Jackson JC, Obremskey W, Bauer R, Greevy R, Cotton BA, Anderson V, Song Y, Ely EW. Long-term cognitive, emotional, and functional outcomes in trauma intensive care unit survivors without intracranial hemorrhage. J Trauma. 2007:62(1):80-8.

7. Himanen L, Portin R, Isoniemi $\mathrm{H}$, Helenius $\mathrm{H}$, Kurki T, Tenovuo O. Longitudinal cognitive changes in traumatic brain injury A 30-year follow-up study. Neurology. 2006: 24: 66(2): 187-92.

8. Rapoport M, Verhoeff NPLG, Reekum RV, Traumatic Brain Injury and Dementia, The Canadian Alzheimer Disease Review; 2004.

9. Sigurdardottir S, Andelic A, Roe C. Postconcusion Symptoms After Traumatic Brain Injury at 3 and 12 Months Post Injury: A Prospective study. Brain Injury. 2009: 23(6):489497.

10. Hoffman JM, Lucas S, Dikmen S. Natural History of Headache after Traumatic Brain Injury. Journal of Neurotrauma, 2011: 28: 1719-1725.

11. Scher AI, Midgette LA, Lipton RB. The Chronification of Headache: Risk Factors for Headache chronification. Headache, 2008: 48: 16-25.

12. Seifert TD, Evans RW.Posttraumatic Headache:A Review. Curr Pain Headache, 2010:1-7.

13. Theeler BJ, Erickson JC. Mild Head Trauma and Chronic Headaches in Returning US Soldiers. Headache, 2009: 49: 529-534.

14. Martins HA, Ribas VR, Martin BM.. Posttraumatic headache. Arq Neuropsiquiatr, 2009: 67(1): 43-45.

15. Couch JR, Lipton RB, Stewart WF. Head or neck injury increases the risk of chronic daily headache: A population-based study. Neurology, 2007, 69: 1169-1177.

16. Beetar JT, Guilmette TJ, Sparadeo FR. Sleep and pain complaints in symptomatic TBI and neurologic populations. Arch Phys Med Rehabil, 1996: 77(12): 1298-1302.
17. Li RHY. Gender Differences in Insomnia-A Study In the Hong kong Chinese Population. Journal of psychosomatic Research. 2002: 53: 601-9.

18. Chang P, Ford D, Mead L. Insomnia in young men and subsequent depression. American Journal of Epidemiology 1997: 146:105-14.

19. Shukla D, Devi BI. Mild traumatic brain injuries in adults. J Neurosci Rural Pract. 2010;1(2):8288. doi: 10.4103/0976-3147.71723.

20. McCrory P, Meeuwisse W, Johnston K. Consensus statement on Concussion in Sport-the 3rd International Conference on Concussion in Sport held in Zurich, November 2008. South African J. 2009;37(2):141-159. doi: 10.3810/psm.2009.06.1721.

21. Gardner RC, Yaffe K. Epidemiology of mild traumatic brain injury and neurodegenerative disease. Mol Cell Neurosci. 2015;66(00):75-80. doi: 10.1016/j.mcn.2015.03.001

22. Badan Penelitian dan Pengembangan Kesehatan. Riset Kesehatan Dasar (RISKESDAS) 2013. Laporan Nasional 2013. Jakarta; 2013: 1-384.

23. Mullally, William J. Concussion. Department of Neurology, Brigham and Women's Faulkner Hospital, Boston, Mass. The American Journal of Medicine Vol 130, No 8 August 2017. http:// doi.org/10.1016/j.amjmed.2017.04.016.

24. Bigler ED. Neuropsychology and clinical neuroscience of persistent postconcussive syndrome. J Int Neuropsychol Soc. 2008;14(1):122. doi: $10.1017 / S 135561770808017 \mathrm{X}$.

25. Leddy JJ, Kozlowski K, Fung M, Pendergast DR, Willer B. Regulatory and autoregulatory physiological dysfunction as a primary characteristic of post concussion syndrome: implications for treatment. NeuroRehabilitation. 2007;22(3):199-205

26. Browne KD, Chen X-H, Meaney DF, Smith DH. Mild Traumatic Brain Injury and Diffuse Axonal Injury in Swine. J Neurotrauma. 2011;28(9):1747-1755. doi: 10.1089/ neu.2011.1913.12.

27. Johnson VE, Stewart W, Smith DH. Axonal Pathology in Traumatic Brain Injury. Exp Neurol. 2013;246:35-43. doi: 10.1016/j. expneurol.2012.01.013.

28. D'souza $M M$, Trivedi $R$, Singh $K$, et al. Traumatic brain injury and the postconcussion syndrome: A diffusion tensor tractography study. Indian J Radiol Imaging. 2015;25(4):404414. doi: 10.4103/0971-3026.169445.

29. Duff J. The Usefulness of Quantitative EEG (QEEG) and Neurotherapy in the Assessment and Treatment of Post-Concussion Syndrome; 2004. doi: $10.1177 / 155005940403500409$.

30. Broshek DK, De Marco AP, Freeman JR. A review of post-concussion syndrome and psychological factors associated with concussion. Brain Inj. 2015;29(2):228-237. doi :10.3109/02699052.2014.974674.

31. Wibowo, S., 1995. Neurotransmitter pada demensia, dalam: S. Wibowo \& S. Sutarni (penyunting), Demensia Aspek Neurobiologi, Epidemiologi \& Tatalaksana,Bagian/SMF I.P.Saraf FK-UGM/RS.Dr.Sardjito, Yogyakarta.

32. Davis, LE., King M.L.,Schulz JL. Disoerder of pain and headache. In: Fundametals of Neurologic Disease Demos Medical
Publishing,New York, 2004:201-7.

33. Hoffer ME, Gottshall KR, Moore R. Characterizing and treating dizziness after mild head trauma. Otol Neurotol 2004: 25(2):135-8.

34. D'Ambrosio R, Perucca E. Epilepsy after head injury. Curr Opin Neurol; 2004: 17(6):731-5.

35. McLean A, Temkin NR. The Behavioral Sequelae of Head Injury. Journal Clinical Neuropsychology: 1984; 5:361-376.

36. Baumann CR, Stocker R, Imhof HG. Hypocretin-1(orexin A) deficiency in acute traumatic brain injury. Neurology 2007: 65(1):147-9.

37. Jamie MZ, Friedman L, Hara RM. Insomnia in the Context of Traumatic Brain Injury. Neurorehabilitation and Neural Repair. 2009: Vol 46;6: 827-836.

38. Li RHY. Gender Differences in Insomnia-A Study In the Hong kong Chinese Population. Journal of psychosomatic Research. 2002: 53: 601-9.

39. Giza CC, Kutcher JS. American Academy of Neurology Concussion Guidelines: March 2013 New Concussion Guidelines: An Analysis. Neurology. 2013;(March):1-10.

40. Lovell MR, Iverson GL, Collins MW, et al. Measurement of Symptoms Following Sports-Related Concussion: Reliability and Normative Data for the Post-Concussion Scale Measurement of Symptoms Following SportsRelated Concussion: Reliability and Normative Data for the Post-Concussion Scale. Appl Neuropsychol. 2006;13(3):3166-3174. doi: 10.1207/s15324826an1303.

41. Kosaka B. Neuropsychological assessment in mild traumatic brain injury: BC Med J. 2006;9(November):447-452.

42. McInnes K, Friesen CL, MacKenzie DE, Westwood DA, Boe SG. Mild Traumatic Brain Injury (mTBI) and chronic cognitive impairment: A scoping review. PLoS One. 2017;12(4). doi: 10.1371/journal.pone.0174847.

43. Register-Mihalik J, Herzog M, Bloom OJ, Fonseca J, Phillips K, De Maio V. Association between initial post-concussion presentation and persistent symptoms at 1-month postconcussion. Br J Sports Med. 2017;51(11):A33 LPA34.

44. Yang C-C, Hua M-S, Tu Y-K, Huang S-J. Early clinical characteristics of patients with persistent post-concussion symptoms: a prospective study. Brain Inj. 2009;23(4):299306. doi: 10.1080/02699050902788543.

45. World Health Organization (WHO). International Statistical Classification of Diseases and Related Health Problem (ICD-10).

46. Ruff RM. Mild traumatic brain injury and neural recovery: Rethinking the debate. NeuroRehabilitation. 2011;28(3):167-180. doi: 10.3233/NRE-20110646.

47. King NS, Crawford S, Wenden FJ, Moss NEG, Wade DT. The Rivermead Post Concussion Symptoms Questionnaire: a measure of symptoms commonly experienced after head injury and its reliability. J Neurol. 1995;242(9):587592. doi: 10.1007/BF00868811.

48. Mercier E, Tardif P, Cameron P, et al. LO94: Prognostic value of neuronspecific enolase (NSE) for prediction of post-concussion 
symptoms following a mild traumatic brain injury: a systematic review. CJEM. 2017;19(S1):S60-S60. doi:DOI: 10.1017/ cem.2017.156.31

49. Smits M, Houston GC, Dippel DWJ, et al. Microstructural brain injury in postconcussion syndrome after minor head injury. Neuroradiology. 2011;53(8):553-563. doi: 10.1007/s00234-010-0774-6.

50. Wing BH, Tucker BJ, Fong AK, Mciff EB, Mark D. Developing the Standard of Care for PostConcussion Treatment : Neuroimaging-Guided Rehabilitation of Neurovascular Coupling, 2016.

51. Hall RCW, Hall RCW, Chapman MJ. Definition, Diagnosis, and Forensic Implications of Postconcussional Syndrome. Psychosomatics. 2005;46(3):195-202. doi:10.1176/appi. psy.46.3.195.
52. Leddy JJ, Sandhu H, Sodhi V, Baker JG, Willer B. Rehabilitation of Concussion and Post-concussion Syndrome. Sports Health. 2012;4(2):147-154. doi:10.1177/1941738111433673.

53. Varriano B, Tomlinson G,Tarazi A, Wennberg R,et al,Age, Gender and Mechanism of Injury Interactions in Post-Concussion Syndrome. The Canadian Journal Of Neurological Sciences Inc. 2018.

54. Bedaso A, Geja E, Ayalew M, Oltaye Z, Duko B, Post-concussion syndrom among patients experiencing head injury attending emergency departement of hawassa university comprehensive spesialized hospital, Hawassa, Soutern Ethiopia, 2018.

55. Powell MR, McCrea MA. Postconcussion Syndrome. In: Kreutzer JS, DeLuca J, Caplan B, eds. Encyclopedia of Clinical Neuropsychology.
New York, NY: Springer New York; 2011:19731974. doi:10.1007/978-0-387-79948-3_270

56. Rathbone, A.T.L et al., 2015. A review of the neuro and systemic inflamatory response in post concussion symptomps : introduction of the "post inflamatory brain syndrome" PIBS. Elsevier, pp 1-16.

57. Permenter CM, Fernández-de Thomas RJ, Sherman Al. Postconcussive Syndrome. [Updated 2020 Sep 3]: StatPearls Publishing; 2020 Jan-. Available from: https://www.ncbi. nlm.nih.gov/books/NBK534786/

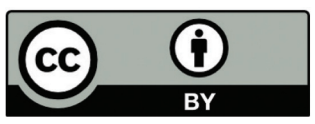

This work is licensed under a Creative Commons Attribution 